\title{
A PROSPECTIVE STUDY OF DENTOALVEOLAR TRAUMA AT THE HOSPITAL DAS CLÍNICAS, SÃO PAULO UNIVERSITY MEDICAL SCHOOL
}

\author{
Fernanda Mendes do Carmo Rezende, Cristiano Gaujac, André Caroli Rocha, \\ Maria Paula Siqueira de Melo Peres
}

Rezende FM do C, Gaujac C, Rocha AC, Peres MPS de M. A prospective study of dentoalveolar trauma at the Hospital das Clínicas, São Paulo University Medical School. Clinics. 2007;62(2):133-8.

PURPOSE: This prospective study evaluated the profile of patients with dentoalveolar trauma assisted at the emergency room of the Oral and Maxillofacial Trauma and Surgery Service at the Hospital das Clínicas, São Paulo University Medical School (Brazil).

METHODS: A prospective study by a questionnaire applied during the first attendance of those patients, in a period of eight months.

RESULTS: The collected data were statistically analyzed. It was observed that $4.7 \%$ of the patients that sought treatment at the Service had sustained dentoalveolar trauma and among these $74 \%$ were male. The most affected individuals were children aged 0 to 5 years and fall was the most prevalent etiologic factor. Avulsion and coronal/crown-root fractures were the most common types of dentoalveolar traumatic injures. As the age increases, the most common etiologic factors are traffic accidents and physical assault.

CONCLUSION: The incidence of dentoalveolar trauma decreased with age and the main etiologic factors in adult patients were traffic accidents and physical assault.

KEYWORDS: Dental trauma. Epidemiology. Fracture. Maxillofacial injuries. Prospective.

\section{INTRODUCTION}

The epidemiologic study of dentoalveolar trauma relies directly on factors such as sampling criteria, age and sex of the surveyed population ${ }^{1}$. Prospective studies significantly reduce the incidence of recording errors from previous traumas, which depend on information from family members or medical files of previous trauma history ${ }^{2}$.

Dentoalveolar traumas have been investigated for several years to gather information about their characteristics, etiology and most commonly affected patients, which is of paramount importance to contribute in preventing their occurrence ${ }^{3,4}$.

Oral and Maxillofacial Trauma and Surgery Service, Hospital das Clínicas, São Paulo University Medical School - São Paulo/SP, Brazil.

Email: cgaujac@gmail.com

Received for publication on July $07,2006$.

Accepted for publication on November 13, 2006.
Studies on dentoalveolar traumas are generally performed at schools in large or middle-sized cities $^{2,4,5}$, middle-sized hospitals ${ }^{6}$ and Dental Schools ${ }^{7,8}$. The city of São Paulo in Brazil is the second largest in Latin America and is an outstanding national medical reference center.

The purpose of this study was to perform a prospective study of dentoalveolar trauma at the Hospital das Clínicas of the Medical School of the University of São Paulo.

\section{METHODS}

A prospective study of dentoalveolar trauma epidemiology was carried out among emergency room patients treated by the internship students of the Oral and Maxillofacial Trauma and Surgery Service at the Hospital das Clínicas, São Paulo University Medical School (Brazil), within an 8 month-period. 
Physical and radiographic examinations were performed and the diagnosis and proper treatment approach were established for each case. Thereafter, some data (sex, age, etiologic factor and frequency of the different types of trauma) were collected using a standard questionnaire form ${ }^{9}$ (Figure 1).

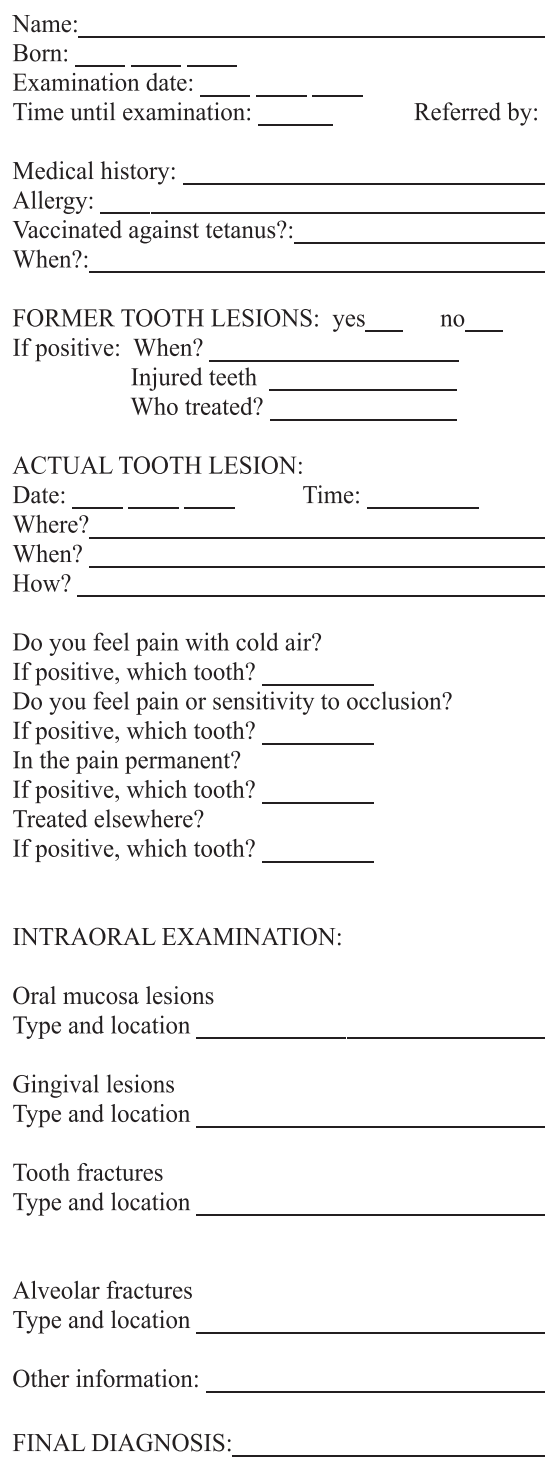

Figure 1 - Questionnaire submitted to the patients treated at the emergency room DENTOALVEOLAR TRAUMATISM

Statistical analysis was performed by Student's t, Kruskal-Wallis and Mann-Whitney tests followed by Dunn's Post Hoc test for multiple comparisons.

\section{RESULTS}

Throughout the study duration, 1,650 patients were referred for treatment at the emergency room of the Oral and
Maxillofacial Trauma and Surgery Service at Hospital das Clínicas. From this total, 78 (4.7\%) patients presented some kind of dentoalveolar trauma.

Among the patients with dentoalveolar trauma, 74\% were male and 26\% were female (Figure 2), which corresponds to a 3:1 ratio. Patients' ages ranged from 9 months to 52 years. Most cases occurred within the first 5 years of life (17 patients; $21.8 \%$ ), followed by the $21-25$ yearold age group (13 patients; $16.7 \%$ ) and the $31-40$ year-old age group (11 patients; 14.1\%) (Figure 3). Analysis of age relative to sex did not show statistically significant difference between the averages for male (19.1 years) and female patients ( 15.6 years) (Student's t-test: $\mathrm{p}=0.305$ and $\mathrm{p}>0.05$, respectively) (Table 1).

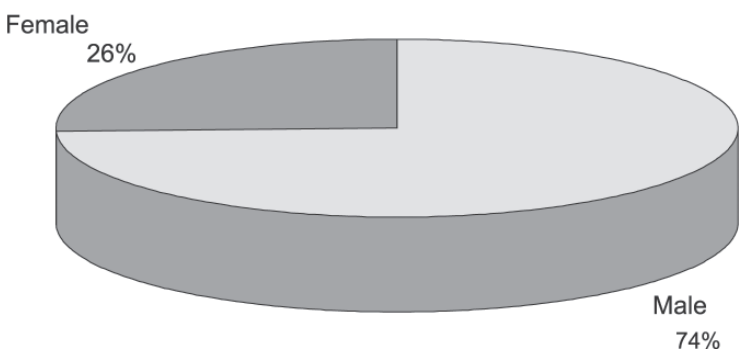

Figure 2 - Patient distribution according to sex

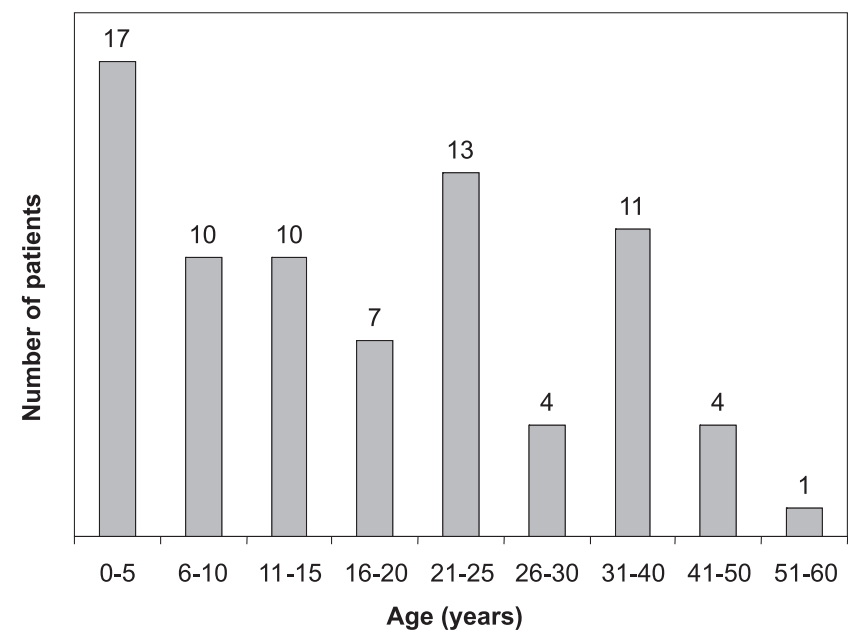

Figure 3 - Patient distribution according to age

Table 1 - Descriptive analysis of age (years) according to sex, compared by Student t-test

\begin{tabular}{lcc}
\hline & Male & Female \\
\hline Average & 19.18 & 15.65 \\
Standard deviation & 13.66 & 11.4 \\
Standard error of average & 1.81 & 2.55 \\
Minimum & 1 & 2 \\
Maximum & 52 & 39 \\
Total number of patients & 57 & 20 \\
\hline
\end{tabular}

Student t-test: $1.033 ; \mathrm{p}=0.305$ 
Table 2 - Descriptive analysis of age (years) according to etiology, compared by the Kruskal-Wallis test

\begin{tabular}{|c|c|c|c|c|c|}
\hline & Traffic Accident & Sports Accident & Assault & Fall & Other \\
\hline Average & 27.9 & 13.3 & 23.77 & 8.78 & 23.67 \\
\hline Standard deviation & 10.94 & 9.26 & 10.41 & 9.08 & 15.28 \\
\hline Standard error of average & 2.51 & 3.28 & 2.89 & 1.75 & 5.09 \\
\hline Minimum & 11 & 2 & 8 & 1 & 3 \\
\hline Maximum & 50 & 34 & 47 & 39 & 52 \\
\hline Total number of patients & 19 & 8 & 13 & 27 & 9 \\
\hline
\end{tabular}

Kruskal-Wallis test: $32.6 ; \mathrm{p}<0.001$

Among the etiologic factors, the most frequent causes of dentoalveolar trauma were falls $(40.8 \%)$, followed by automobile accidents (37.4\%), which involved car, motorcycle and bicycle accidents as well as overruns. Physical assault (punches, kicks and firearm wounds) corresponded to $11.6 \%$ of the cases, while collision with objects represented the third highest incidence $(4.8 \%)$, followed by sports accidents $(3.4 \%)$ and working site accidents $(2 \%)$ (Figure. 4).

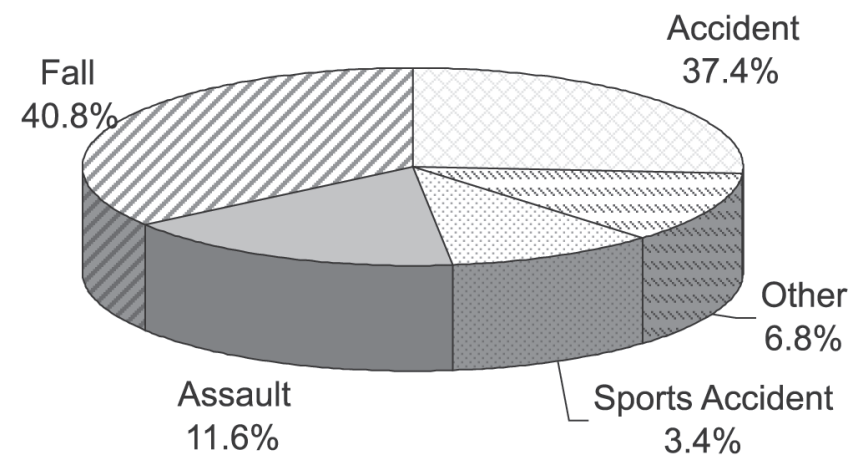

Figure 4 - Patient distribution according to etiology

Analysis of age relative to etiologic factor revealed that among patients aged 0 to 5 years, fall was the most prevalent cause of dentoalveolar traumas. Traffic accidents and aggressions were the most frequent in the 21-25 and 31-40 year-old age groups. Most patients with dentoalveolar traumatic injuries resulting from engagement in sport activities were in the 10-15 year-old age group. Victims of traffic accidents were 27.7 years old on average while the mean age of victims of physical assault was 23.7 years. However, among the patients that had sustained traumatic dentoalveolar injuries as a consequence of falls, the average age dropped to 8.7 years. Variation of age relative to the etiologic factor exhibited statistical significance (Kruskal-Wallis test and Dunn's multiple comparison test) (Table 2).

Physical assault was the most frequently reported cause of dentoalveolar trauma in men $(92.3 \%)$. Nevertheless, no significant difference between sexes was observed when fall victims were evaluated $(45 \%$ were men and $55 \%$ were women) (Table 3).
Table 3 - Distribution of the etiologies by sex (\%)

\begin{tabular}{lcc}
\hline & Female & Male \\
\hline Traffic accidents & 25.0 & 75.0 \\
Sports accidents & 12.5 & 87.5 \\
Assault & 7.7 & 92.3 \\
Fall & 55.0 & 45.0 \\
Other & 22.2 & 77.8 \\
\hline
\end{tabular}

Avulsion and coronal/crown-root fractures were the most common types of dentoalveolar traumatic injuries, corresponding to $20.4 \%$ and $19.7 \%$ of all cases surveyed, respectively. Alveolar fractures were also relatively common (17\%), followed by lateral luxation (13.6\%). Concussions and subluxations were the least frequent dentoalveolar traumas, accounting for only $1.4 \%$ and $3.4 \%$ of the cases, respectively (Figure 5).

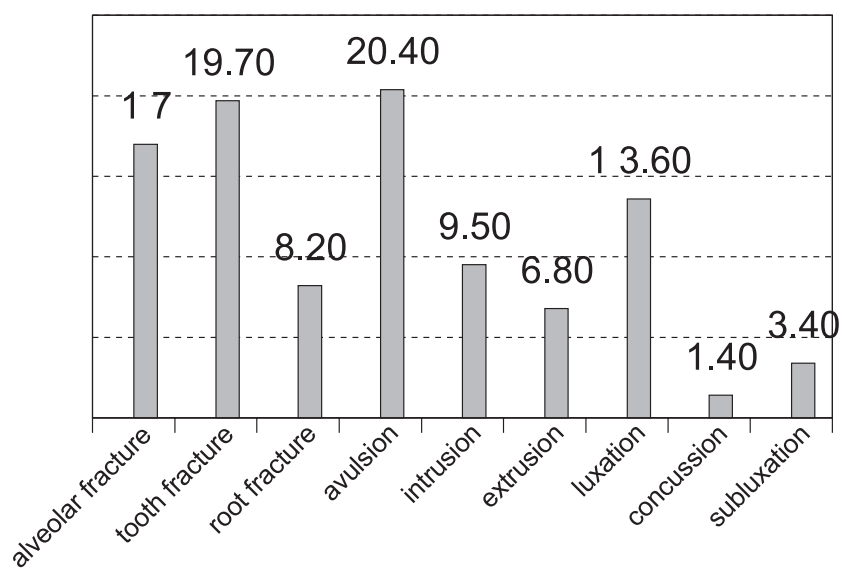

Figure 5 - Frequency of the different dentoalveolar injuries identified in the study

Most alveolar fractures occurred in patients involved in traffic accidents and accounted for the most severe dentoalveolar traumas. Severe dentoalveolar injuries such as alveolar fractures and avulsions were also observed in cases of physical aggressions. Fall victims presented most frequently lateral and intrusive luxations, tooth fractures and avulsions, with small differences in the incidence of each type of trauma (Table 4). 
Table 4 - Distribution of dentoalveolar injuries according to the etiology

\begin{tabular}{|c|c|c|c|c|c|c|c|}
\hline & Traffic Accident & Sports & Accident & Assault & Fall & $\begin{array}{c}\text { Collision with } \\
\text { object }\end{array}$ & $\begin{array}{c}\text { Working Site } \\
\text { Accident }\end{array}$ \\
\hline Alveolar fracture & 13 & & 0 & 7 & 5 & 0 & 0 \\
\hline Tooth fracture & 11 & & 2 & 2 & 12 & 1 & 1 \\
\hline Root fracture & 5 & & 0 & 2 & 3 & 1 & 1 \\
\hline Avulsion & 14 & & 1 & 5 & 9 & 0 & 1 \\
\hline Intrusion & 3 & & 0 & 0 & 10 & 1 & 0 \\
\hline Extrusion & 2 & & 0 & 0 & 7 & 1 & 0 \\
\hline Luxation & 4 & & 1 & 1 & 11 & 3 & 0 \\
\hline Concussion & 1 & & 0 & 0 & 1 & 0 & 0 \\
\hline Subluxation & 2 & & 1 & 0 & 2 & 0 & 0 \\
\hline
\end{tabular}

\section{DISCUSSION}

Different frequencies of dentoalveolar trauma are found in the literature, depending on the employed methodology, i.e., $35 \%^{10}, 24.4 \%^{11}$ and $11.1 \%{ }^{12}$, which hampers the comparison of incidences. This variation may be influenced by the type of dentition (primary - 30\%; permanent - 22\%) 13 $^{13}$ and patients' age (the frequency of dentoalveolar trauma has been shown to vary inversely proportional to age and incidences between 5.2 and $11.7 \%$ have been observed in different age groups $)^{14}$. A great part of these studies investigated dental trauma in schoolchildren by means of clinical examinations and questionnaires. Therefore, the incidence becomes cumulative, which might increase significantly the number of cases. On the other hand, the number of dentoalveolar traumas decreases significantly when epidemiologic studies are performed in a hospital environment. This has been reported by Galea ${ }^{15}$, who found an incidence of $1.8 \%$, close to the one observed in present the study $(4.7 \%)$.

The increase of accidents involving women results from the greater female engagement in activities formerly restricted to men. At the time of writing, women participate in every sports activity, including radical sports and automobile races. Even so, dentoalveolar traumatic injuries are still more prevalent among male individuals at a ratio of $2: 1$ or $3: 1^{7,16}$, as found in the present study $(74.3 \%)$. Petti and Tarsitani ${ }^{17}$ reported a greater prevalence of dental trauma cases for females, but the patients in their study were 10 years old.

There is a lesser incidence of dentoalveolar trauma as age increases ${ }^{8,18}$. This was also observed in the present as most cases of trauma occurred in patients aged 0 to 5 years $(21.8 \%)$ and falling was the most frequent cause. These findings are probably explained by the fact that this is a phase of motor skill development and therefore children of this age group are more susceptible to falls and might hit the face against the floor or obstacles. The second highest frequency of dentoalveolar trauma was observed among young adults aged 21 to 25 years (16.7\% of all cases). For this group and for the $31-40$ year-old age group (14.1\% of all cases), the most common causes of dentoalveolar traumatic injuries were traffic accidents and aggressions. It has been shown that when the survey includes former dental trauma history ${ }^{10,11,14,19}$, data become cumulative, which means that the older the patient, the greater the probability of trauma occurrence in his/her life, reversing the proportional ratio.

The findings of this survey revealed that fall was the most frequent etiologic factor, corresponding to almost forty-one percent of all cases of dentoalveolar trauma, which agrees with the outcomes of previous studies ${ }^{8,15,20-23}$. Few cases of dentoalveolar traumatic injuries were attributed to sports accidents (3.4\%), which is consistent with the results of other authors ${ }^{20,24}$.

Avulsions (20.4\%) and coronal/crown-root fractures $(19.7 \%)$ were the most frequent types of dentoalveolar injury. The different classification criteria found in the literature makes it difficult to compare the outcomes of different studies. Even so, crown fractures, either complex or not, involving enamel or enamel/dentin, are the most commonly reported types of dentoalveolar traumatic injury ${ }^{10-}$ 12,15,24-27. However, da Silva et al. ${ }^{6}$ found avulsion and luxation as the most prevalent dentoalveolar traumas.

Most patients assisted at the emergency room within the surveyed period presented moderate to severe injuries, while simple traumas were considerably less frequent. It probably occurred because this is a tertiary care university hospital that offers specialized assistance in several areas and to which complicated cases are referred to from other cities, states and even dental offices that are not able to provide the required treatment. These findings corroborate those of Andreasen ${ }^{28}$, who reported that severe traumas such as luxation and bone fracture were more frequent among hospital patients, whereas crown fractures without pulp exposure were most commonly found in school children.

The severity of lesions is directly related to the kind of trauma suffered by each patient, ranging from automobile 
accident (high impact) to a mere fall from his/her own height (low impact). The most severe lesions, such as avulsions and dentoalveolar fractures, may affect the development the patient's maxillary bones if not properly treated, especially in case of growing-age children. Therefore, the early diagnosis and treatment are of paramount importance.

In some patients, the presence of other associated face fractures and cranioencephalic traumas was observed. A patient reported a rapid loss of consciousness, nausea and posttraumatic headache. Such evidences suggest the need for development of a future study relating the cranioencephalic trauma to the dentoalveolar trauma.

Several measures for the prevention of dentoalveolar trauma may be established. In order to reduce the incidence of traumas due to falls in children, rubber floors could be installed in the places where accidents with children most likely occur, such as school and park playgrounds. For the elderly, installation of helping bars and anti-skid floors would be of great help. Traffic educational programs for car drivers, bicycle drivers and pedestrians alike would reduce the possibility of accidents. To prevent contact sport accidents, the use of mouth protectors is advisable. These are some of the possible measures to reduce the incidence of dentoalveolar traumas.

\section{CONCLUSION}

Based on the findings and numbers of this prospective study performed in the largest hospital complex in Latin America, it may be concluded that dentoalveolar trauma was most common in male patients and predominantly occurred within the first decade of life, mainly due to falls. Avulsion and coronal/crown-root fractures were the most common types of dentoalveolar traumatic injures. The incidence of dentoalveolar trauma decreased with age and the main etiologic factors in adult patients were traffic accidents and physical aggression.

\section{RESUMO}

Rezende FM do C, Gaujac C, Rocha AC, Peres MPS de M. Estudo prospectivo do trauma dento-alveolar no Hospital das Clínicas da Faculdade de Medicina da Universidade de São Paulo. Clinics. 2007;62(2):133-8.

PROPOSIÇÃO: Avaliar o perfil dos pacientes, com traumatismo dento-alveolar, atendidos no Pronto-Socorro do Serviço de Cirurgia e Traumatologia Buco-Maxilo-Facial do Hospital das Clínicas da Faculdade de Medicina da Universidade de São Paulo (Brasil).

MÉTODOS: Foi realizado um estudo prospectivo, através de um questionário aplicado, durante o primeiro atendimento desses pacientes, em um período de oito meses.

RESULTADOS: Os dados obtidos foram analisados estatisticamente e verificou-se que dos pacientes atendidos 4,7\% apresentavam traumatismo dento-alveolar, e destes, $74 \%$ eram do gênero masculino; as crianças de 0 a 5 anos eram as mais acometidas, a etiologia mais comum foi a queda; e o tipos de traumas mais freqüentes foram a avulsão e fratura dental. A medida que a idade avança os fatores etiológicos mais comuns são os acidentes de trânsito e as agressões físicas.

CONCLUSÃO: A incidência de trauma de dentoalveolar diminuiu com a idade e o principal fator etiologico nos pacientes adulto foi acidentes de tráfico e agressão física.

UNITERMOS: Trauma dental. Epidemiologia. Fratura. Trauma maxilo-facial. Prospectivo.

\section{REFERENCES}

1. Andreasen JO, Andreasen FM. Classification, Etiology and Epidemiology. In: Textbook and color atlas of traumatic injuries to the teeth. Andreasen JO, Andreasen FM (editors). 3rd ed. Copenhagen: Munksgaard, 2001. p.151-180.

2. Grimm S, Frazão P, Antunes JLF, Castellanos RA, Narvai PC. Dental injury among Brazilian schoolchildren in the state of São Paulo. Dent Traumatol 2004;20:134-8.

3. Skaare AB, Jacobsen I. Etiological factors related to dental injuries in Norwegians aged 7-18 years. Dent Traumatol 2003;19:304-8.
4. Traebert J, Peres MA, Blank V, Böell RS, Pietruza JA. Prevalence of traumatic injury and associated factors among 12-year-old school children in Florianópolis, Brazil. Dent Traumatol 2003;19:15-8.

5. Cortes MI, Marcenes W, Sheiham A. Prevalence and correlates of traumatic injuries to the permanent teeth of schoolchildren aged 9-14 years in Belo Horizonte, Brazil. Dent Traumatol 2001;17(1):22-6.

6. da Silva AC, Passeri LA, Mazzonetto R, de Moraes M, Moreira RWF. Incidence of dental trauma associated with facial trauma in Brazil: a 1year evaluation. Dent Traumatol 2004;20:06-11. 
7. Zuhal K, Semra OEM, Hüseyin K. Traumatic injuries of the permanent incisor in children in southern Turkey: a retrospective study. Dent Traumatol 2005;21:20-5.

8. Sandalli N, Cildir S, Guler N. Clinical investigation of traumatic injuries in Yeditepe University, Turkey during the last 3 years. Dent Traumatol 2005;21:188-94.

9. Andreasen JO, Andreasen FM, Bakland LK, Flores MT. Traumatic dental injuries. A. manual. 1st ed. Copenhagen: Munksgaard; 2000.

10. Garcia-Godoi F, Mórban-Laucer F, Corominas LR, Franjul RA, Noyola M. Traumatic dental injuries in preschoolchildren from Santo Domingo. Community Dent Oral Epidemiol 1983;11(2):127-30.

11. Yagot KN, Nazhat NY, Kuder SA. Traumatic dental injuries in nursery schoolchildren from Baghdad, Iraq. Community Dent Oral Epidemiol 1988;16(5):292-3.

12. Zadik D. A survey of traumatized primary anterior teeth in Jerusalem preschool children. Community Dent Oral Epidemiol 1976;4(4):14951.

13. Andreasen JO, Ravn JJ. Epidemiology of traumatic dental injuries to primary and permanent teeth in a Danish population sample. Int J Oral Surg 1972;1:235-9.

14. Marcenes W, Al beiruti N, Tayfour D, Issa S. Epidemiology of traumatic injuries to the permanent incisors of 9-12-year-old schoolchildren in Damascus, Syria. Endod Dent Traumatol 1999;15(3):117-23.

15. Galea H. An investigation of dental injuries treated in an acute care general hospital. JADA 1984;109(3):434-8.

16. Gutmann JL, Gutmann MSE. Cause, incidence and prevention of trauma to teeth. Dent Clin North Am 1995;39(1):1-13.

17. Petti S, Tarsitani G. Traumatic injuries to anterior teeth in Italian schoolchildren: prevalence and risk factors. Endod Dent Traumatol 1996;12(4):294-7.
18. Andreasen JO. Etiology and pathogenesis of traumatic dental injuries. Scand J dent Res 1970;78(4):329-342.

19. Mestrinho HD, Bezerra ACB, Carvalho JC. Traumatic dental injuries in Brazilian pre-school children. Braz Dent J 1998;9(2):101-4.

20. Uji T, Teramoto T. Occurrence of traumatic injuries in the oromaxillary region of children in a Japanese prefecture. Endod Dent Traumatol 1988;4(2):63-9.

21. Blinkhorn FA. The aetiology of dento-alveolar injuries and factors influencing attendance for emergency care of adolescents in the North West of England. Endod Dent Traumatol 2000;16(4):162-5.

22. Sae-Lim V, Tan HH, Yuen KW. Traumatic dental injuries at the Accident and Emergency Department of Singapore General Hospital. Endod Dent Traumatol 1995;11(1):32-6.

23. Martin IG, Daly CG, Liew VP. After-hours treatment of anterior denta trauma in Newcastle and western Sydney: a four-year study. Austr Dent J 1990;35(1):27-31.

24. Oikarinen K, Kassila O. Causes and types of traumatic tooth injuries treated in a public dental health clinic. Endod Dent Traumatol 1987;3(4):172-7.

25. Rusmah M. Traumatized anterior teeth in children. A 24-month followup study. Austr Dent J 1990;35(5):430-3.

26. Lee-Knight CT, Harrison EL, Price CJ. Dental injuries at the 1989 Canada Games: An epidemiological study. J Can Dent Assoc 1992;58(10):810-4

27. Hargreaves JA, Matejka JM, Cleaton-Jones PE, Williams S. Anterior tooth trauma in eleven-year-old South African children. J Dent Child 1995;62(5):353-5.

28. Andreasen, J.O. Lesiones Traumaticas de los dientes. $3^{\mathrm{a}}$ ed. Barcelona: Labor, 1984. p. 41-51. 